\title{
GERMINAÇÃO, QUALIDADE SANITÁRIA E ARMAZENAMENTO DE SEMENTES DE CANAFÍSTULA (Peltophorum dubium) ${ }^{1}$
}

\begin{abstract}
Adriana Martinelli Seneme ${ }^{2}$, Edilberto Possamai ${ }^{3}$, Silvelena Vanzolini ${ }^{4}$ e Cibele Chalita Martins ${ }^{4}$
RESUMO - Neste trabalho, objetivou-se avaliar o efeito de métodos de superação de dormência e do ambiente de armazenamento sobre a qualidade fisiológica e fitopatológica das sementes de canafístula (Peltophorum dubium). As sementes foram submetidas aos seguintes tratamentos de superação de dormência: escarificação com lixa (200); imersão em água na temperatura ambiente, durante 24 e 72 h; imersão em ácido sulfúrico por 2, 6, 10, 15, 20 e 30 min; imersão em água quente (70, 80 e 90 C); e umedecimento do substrato com solução de $\mathrm{KNO}_{3}(0,2 \%)$. As sementes foram armazenadas na temperatura ambiente e a $10 \mathrm{C}$ por 210 dias. Os efeitos dos tratamentos e do armazenamento foram avaliados por meio do teor de água, teste de germinação (cinco repetições de 30 sementes), de comprimento de plântulas e sanidade (400 sementes), com incubação por oito dias (22-25 C). Na análise estatística dos dados, utilizou-se o delineamento experimental inteiramente casualizado em esquema fatorial 2 x 14 (condições de armazenamento x tratamentos para a superação da dormência). As médias foram comparadas pelo teste de Tukey $(\mathrm{P}>0,5)$. Com relação às sementes não armazenadas, os melhores tratamentos para superar a dormência e promover a germinação foram escarificação com lixa ou ácido sulfúrico por 15 a 30 min; quanto às sementes armazenadas, houve a imersão em água quente (70 a $80^{\circ} \mathrm{C}$ ). Os fungos detectados nas sementes foram Pestalotia sp., Alternaria sp., Rhizopus sp., Nigrospora sp., Curvularia sp., Fusarium sp., Rhizoctonia sp., Aspergillus sp., Cladosporium sp. e Fusarium semitectum.
\end{abstract}

Palavras-chave: Qualidade sanitária, Recomposição florestal e Nativa.

\section{GERMINATION, SANITARY QUALITY AND STORAGE OF SEEDS OF Peltophorum dubium (Spreng) TAUB}

\begin{abstract}
The objective of this work was to evaluate the effect of dormancy overcoming treatments and storage environment on physiological and phitopathologic quality of canafístula seeds (Peltophorum dubium). Seeds were submitted to the following treatments of dormnancy superação: scarification with sandpaper (200); immersion in water at room temperature for 24 and 72 hours; (c) immersion in sulfuric acid for 2, 6, 10, 15, 20 and 30 minutes); immersion in hot water $\left(70,80\right.$ and $\left.90^{\circ} \mathrm{C}\right) ;(e)$ moistening of the substratum with $\mathrm{KNO}_{3}$ solution of $(0.2 \%)$. Seeds were stored at room temperature and at $10^{\circ} \mathrm{C}$ for 210 days. Effects of treatments and storage were evaluated by water content, germination test (five replicates of 30 seeds), seedlings length and sanity test (400 seeds), with eight-day incubation. It was used a complete random experimental design for data statistics analysis with a $2 \times 14$ factorial design (storage conditions $x$ treatments for dormancy overcoming). Means were compared by the Tukey test $(P>0.5)$. Regarding non-stored seeds, the best treatments to overcome dormancy and to promote germination were scarification with sandpaper or sulfuric acid for 15 and 30 minutes; regarding stored seeds, there was immersion in hot water $\left(70\right.$ and $\left.80^{\circ} \mathrm{C}\right)$. Fungi detected in the samples were Pestalotia sp., Alternaria sp., Rhizopus sp., Nigrospora sp., Curvularia sp., Fusarium sp., Rhizoctonia sp., Aspergillus sp., Cladosporium sp. and Fusarium semitectum.
\end{abstract}

Keywords:Sanitary quality, Forest recomposition and Native.

\footnotetext{
${ }^{1}$ Recebido em 10.12.2009 e aceito para publicação em 15.11.2011.

${ }^{2}$ Faculdades Integradas "Espírita", FACIBEN, Brasil. E-mail: <adriana.seneme@hotmail.com>.

${ }^{3}$ Universidade Federal do Paraná, UFPR, Brasil. E-mail: < possamai@ufpr.br>.

${ }^{4}$ Universidade Estadual Paulista Júlio de Mesquita Filho, Campus de Jaboticabal, UNESP, Brasil. E-mail: <sv.segato@bol.com.br> e<cibele@fca.unesp.br>.
} 


\section{INTRODUÇÃO}

Peltophorum dubium (Spreng) Taub (Leguminosae - Caesalpinoideae) é uma espécie nativa rústica e de rápido crescimento, conhecida vulgarmente como canafístula, farinha-seca, faveira, tamboril-bravo, ibirá e puitá. Ótima para a composição de reflorestamento misto em áreas degradadas de preservação permanente e muito empregada no paisagismo como planta ornamental. Sua madeira é utilizada na construção civil e na marcenaria. A germinação das sementes deve ser feita em substrato rico em matéria orgânica, e sua emergência ocorre de 15 a 30 dias após a semeadura, apresentando bom índice de germinação (CARVALHO, 1994). No entanto, quando as sementes são colhidas muito secas a germinação é lenta e irregular, apresentando dormência tegumentar (CARVALHO, 1994). Alguns tratamentos de superação de dormência podem ser utilizados para sementes com dureza tegumentar, como a escarificação com lixa, cortes do tegumento na região oposta à radícula, imersão em ácido sulfúrico concentrado, imersão em água na temperatura ambiente durante 24 h e imersão em água quente, embora esses métodos tenham eficiência diversa, dependendo da espécie e da procedência das sementes (BRASIL, 2009; MARTINS; NAKAGAWA, 2008). Bianchetti e Ramos (1981) constataram que a imersão das sementes de $P$. dubium em ácido sulfúrico concentrado por períodos de 2 a 10 min e em água quente nas temperaturas iniciais de 70 a $95{ }^{\circ} \mathrm{C}$, seguida de repouso na temperatura ambiente por $24 \mathrm{~h}$, foram tratamentos que superaram a dormência e possibilitaram valores de germinação em torno de 90 e 69\%, respectivamente. De acordo com Durigan et al. (1997), a imersão em água quente a $90{ }^{\circ} \mathrm{C}$ até retornar à temperatura ambiente e a imersão em ácido sulfúrico concentrado por 15 min e após a lavagem em água corrente durante 10 min são métodos eficientes para superar a dormência das sementes de canafístula. Após os tratamentos, as sementes demoram de 10 a 15 dias para germinar, alcançando índices de 80 a $90 \%$ de germinação. Na condução do teste de germinação, há a possibilidade de utilizar as temperaturas de 20,25 ou $30^{\circ} \mathrm{C}$ e os substratos areia, vermiculita, papel mata-borrão verde ou branco ou papel-toalha (BIANCHETTI; RAMOS, 1981). Também há recomendação de uso de substrato areia, nas temperaturas de 26 e $30{ }^{\circ} \mathrm{C}$, papel mata-borrão em 22 e $26^{\circ} \mathrm{C}$ e papel-toalha em 24 e $26^{\circ} \mathrm{C}$ (CARVALHO, 1994).
Sementes de canafístula com germinação inicial de $99 \%$ e armazenadas durante 25 meses em saco de papel "Kraft” em câmara seca (temperatura ambiente e UR de 50\%) apresentaram, após esse período, germinação de $92 \%$ e em ambiente de sala (sem controle de temperatura e umidade relativa), germinação de $82 \%$. Após sete anos de armazenamento em tamborete em câmara fria ( 3 a $5^{\circ} \mathrm{C}$ ), sementes com germinação inicial de 95\% apresentaram 41\% de germinação (CARVALHO, 1994). Segundo Durigan et al. (1997), sementes de canafístula conservam sua viabilidade durante quatro anos se armazenadas em ambiente seco.

Neste trabalho, teve-se por objetivo avaliar o efeito de métodos de superação de dormência e do ambiente de armazenamento sobre as qualidades fisiológica e fitopatológica das sementes de canafístula.

\section{MATERIAL E MÉTODOS}

Sementes de P. dubium provenientes do Instituto de Pesquisas Florestais (IPEF) de Piracicaba, SP, em 2003, foram avaliadas quanto ao teor de água e peso de 100 sementes (BRASIL, 2009); e em seguida foram submetidas aos seguintes tratamentos para a superação da dormência: (a) escarificação mecânica com lixa (200); (b) imersão em água na temperatura ambiente, durante 24 e 72 h; (c) imersão em ácido sulfúrico concentrado por 2, 6, 10, 15, 20 e 30 min e após lavagem em água corrente; (d) imersão em água quente nas temperaturas de 70,80 e $90{ }^{\circ} \mathrm{C}$ (50 mL de água/150 sementes) e permanência na água fora do aquecimento, durante 24 h; e (e) umedecimento do substrato com solução de $\mathrm{KNO}_{3}(0,2 \%)$.

Os efeitos dos tratamentos foram avaliados por meio do teste de germinação: logo após os tratamentos para a superação da dormência, realizou-se a avaliação da germinação em caixas de plástico transparente com tampa em substrato papel-filtro, em temperatura constante de $25^{\circ} \mathrm{C}$. A avaliação foi efetuada aos cinco e 10 dias após a instalação do ensaio. Aproveitando o teste de germinação, avaliaram-se ainda o peso de matéria seca de plântula (g) e a porcentagem de sementes mortas e dormentes; e o teste de sanidade, foram utilizadas 400 sementes (quatro subamostras de 100 sementes). A instalação foi feita em caixas de plástico transparente em substrato papel-filtro autoclavado e esterilizado e umedecido com água destilada. As sementes permaneceram incubadas por oito dias em ambiente 
de sala $\left(22-25^{\circ} \mathrm{C}\right)$ previamente desinfestada. Após esse período, os fungos foram identificados com o auxílio de microscópio e do manual de Barnett e Barry (1976).

As sementes submetidas aos tratamentos de superação de dormência foram secas e armazenadas por 210 dias e acondicionadas em sacos de polipropileno duplo (embalagem impermeável), mantidos em condições de ambiente de laboratório (sem controle de temperatura) e em câmara a $10^{\circ} \mathrm{C}$. Após 210 dias de armazenamento, efetuaram-se s testes de germinação, de determinação do teor de água e de sanidade, conforme descrito anteriormente.

Os dados de teor de água, massa de 100 sementes e teste de sanidade não foram submetidos à análise estatística. Os demais parâmetros foram analisados por meio de delineamento experimental inteiramente casualizado, com cinco repetições de 30 sementes. No estudo do armazenamento, utilizou-se um esquema fatorial 2 x 14 (condições de armazenamento x tratamentos para a superação da dormência), sendo as médias comparadas pelo teste de Tukey $(\mathrm{P}>0,5)$. Os dados em porcentagem foram transformados em (arco-seno x) 1/2, e parâmetros que apresentaram valores nulos tiveram os dados transformados em arco- seno $(x+0,5)$. Nas tabelas são apresentadas as médias originais.

\section{RESULTADOS}

As sementes apresentaram valores de 8,6\% para teor de água e 4,63 g para peso de 100 sementes. Após 210 dias de armazenamento, o teor de água das sementes dos diversos tratamentos foi similar, apresentando valores de $8,7 \pm 2 \%$. Os tratamentos com as maiores porcentagens de germinação e menores valores de sementes dormentes foram escarificação com lixa e com ácido sulfúrico (15, 20 e 30 min), os quais foram semelhantes estatisticamente entre si (Figuras 1 e 2).

O tratamento de imersão das sementes durante 24 h em água foi o método que resultou em plântulas mais leves (peso médio de 0,013 g) e, portanto, com menor vigor avaliado pelo peso de matéria seca, diferindo significativamente dos tratamentos lixa, ácido sulfúrico (10 e 20 min) e água quente a $70{ }^{\circ} \mathrm{C}$ (Figura 3). O método ocasionou ainda um dos valores mais baixos de germinação (8\%), em razão, principalmente, do elevado número de sementes dormentes (86\%) (Figura 2).

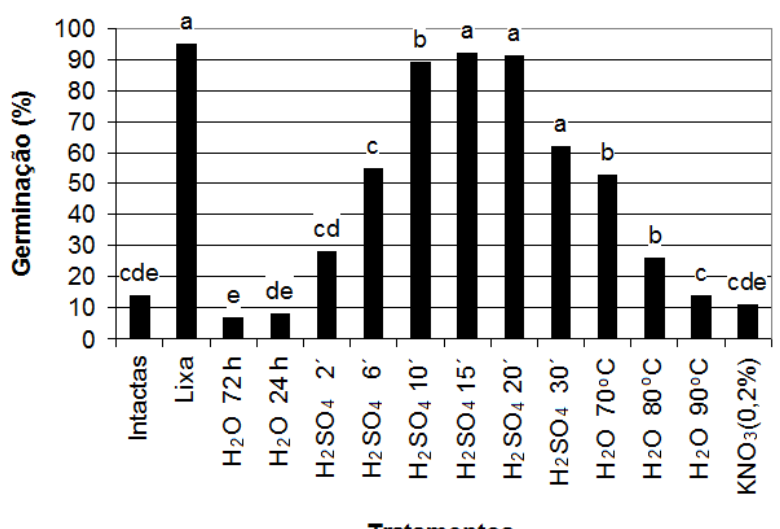

Tratamentos

Figura 1 - Germinação de sementes de canafístula (Peltophorum dubium) após a aplicação de diferentes tratamentos para a superação da dormência $(\mathrm{CV}=12,9 \%)$, Curitiba, 2003.

Figure 1 - Germination of canafistula seeds (Peltophorum dubium) after dormancy overcoming treatments (CV = 12.9\%), Curitiba, 2003.

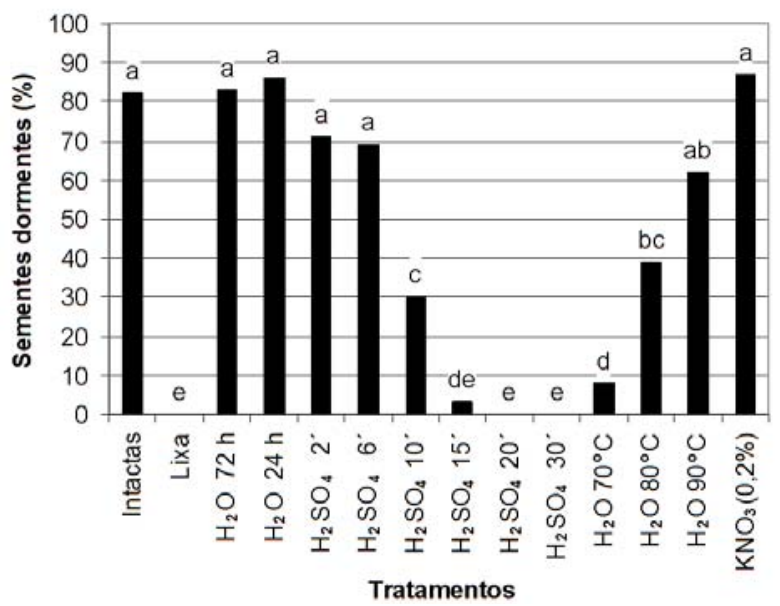

Figura 2 - Porcentagem de sementes dormentes oriundas do teste de germinação de canafístula após a aplicação de diferentes tratamentos para a superação da dormência (CV = 13,3\%), Curitiba, 2003.

Figure 2-Percentage of dormant seeds resulting from canafístula germination test after dormancy overcoming treatments $(\mathrm{CV}=13.3 \%)$, Curitiba, 2003.

Pelos resultados do teste de sanidade das sementes de $P$. dubium realizado antes do armazenamento, foram detectadas médias de $14 \%$ das sementes com Pestalotia sp. e 6\% com Alternaria sp.; valores inferiores a $1 \%$ foram constatados nos fungos Rhizopus sp., Nigrospora sp., Curvularia sp., Fusarium sp., Rhizoctonia sp. e Aspergillus sp.

Revista Árvore, Viçosa-MG, v.36, n.1, p.01-06, 2012 
Houve interação significativa entre os fatores local de armazenamento e tratamentos para a superação da dormência visando à germinação das sementes e sementes dormentes (Tabela 1). O tratamento que proporcionou a melhor germinação após o armazenamento em ambas as condições ambientais avaliadas (temperatura ambiente e a $10^{\circ} \mathrm{C}$ ) foi a imersão das sementes em água quente a 70 e $80^{\circ} \mathrm{C}$.

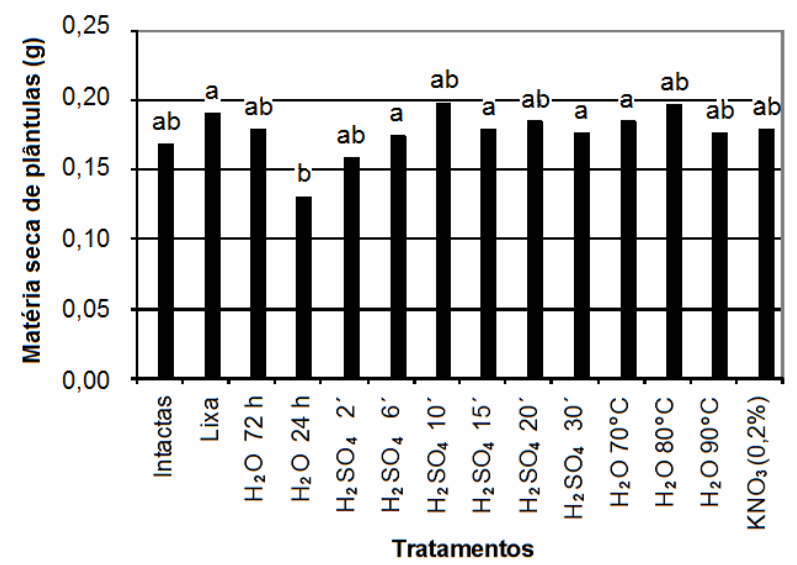

Figura 3 - Peso de matéria seca de plântulas de canafístula aos 12 dias após a instalação do teste de germinação $(\mathrm{CV}=13,2 \%)$.

Figure 3 -Dry matter weight of canafistula seedlings 12 days after setting up of the germination test (CV = 13.2\%).

\section{DISCUSSAO}

Após 210 dias de armazenamento, a manutenção do teor de água em valores similares aos iniciais e relativamente baixos $(8,7 \pm 2 \%)$ em ambas as condições de temperatura de armazenamento permitiu verificar que a embalagem impermeável utilizada foi eficiente, impedindo a troca de água vapor com o meio e possibilitando que a germinação fosse mantida relativamente alta nos tratamentos testemunha e na escarificação com lixa em condições de temperatura de $10{ }^{\circ} \mathrm{C}$, favorável ao armazenamento de sementes ortodoxas como a de canafístula (CARVALHO, 1994; DURIGAN et al., 1997).

Os tratamentos escarificação com lixa ou imersão em ácido sulfúrico (15, 20 ou $30 \mathrm{~min}$ ) promoveram a melhor germinação das sementes, com menores valores de sementes mortas e de sementes dormentes, originando plântulas mais pesadas (Figuras 1, 2 e 3). Estudando dois lotes de sementes de canafístula, Oliveira et al. (2003) verificaram que os melhores tratamentos para a superação da dormência foram o uso de lixa, e a imersão em ácido sulfúrico por 15 min e em água quente $\left(95^{\circ} \mathrm{C}\right)$. Nascimento et al. (2009) observaram, também, que o uso da lixa e a imersão no ácido sulfúrico por 15 min foram eficientes para promover a germinação de sementes de faveira (Parkia platyicephala Benth.), cujo

Tabela 1 - Potagem de germinação, sementes mortas e dormentes de canafístula (Peltophorum dubium) após a superação de dormência e armazenamento por 210 dias em condições de ambiente de laboratório e em câmara a $10{ }^{\circ} \mathrm{C}$, Curitiba, 2004.

Table 1 - Percentage of germination, dead and dormant seeds of canafistula (Peltophorum dubium) after dormancy overcoming treatment and storage in laboratory environment conditions and in chamber at $10^{\circ} \mathrm{C}$ for 210 days, Curitiba, 2004.

\begin{tabular}{|c|c|c|c|c|c|c|}
\hline \multirow[t]{2}{*}{ Tratamentos } & \multicolumn{2}{|c|}{ Germinação } & \multicolumn{2}{|c|}{ Sementes Dormentes } & \multicolumn{2}{|c|}{ Sementes Mortas } \\
\hline & Ambiente & $10^{\circ} \mathrm{C}$ & Ambiente & $10^{\circ} \mathrm{C}$ & Ambiente & $10^{\circ} \mathrm{C}$ \\
\hline Intactas & $30 \operatorname{def}^{1} \mathrm{~A}$ & 25 e $A$ & 63 а $A$ & 66 а $A$ & $7 \mathrm{~b} \mathrm{~A}$ & $2 \mathrm{~b} \mathrm{~B}$ \\
\hline Lixa & 25 ef B & 87 a $A$ & 0 e $A$ & 0 e $A$ & 54 a $A$ & $3 \mathrm{~b} \mathrm{~A}$ \\
\hline $\mathrm{H}_{2} \mathrm{O} 72 \mathrm{~h}$ & $16 \mathrm{f} \mathrm{A}$ & 24 e $A$ & 64 a $A$ & 64 a $A$ & $11 \mathrm{~b} \mathrm{~A}$ & $4 \mathrm{~b} \mathrm{~B}$ \\
\hline $\mathrm{H}_{2}^{2} \mathrm{O} 24 \mathrm{~h}$ & $26 \operatorname{def} A$ & 22 e $A$ & $54 \mathrm{ab} A$ & 67 a $A$ & $11 \mathrm{~b} \mathrm{~A}$ & $9 \mathrm{~b} \mathrm{~A}$ \\
\hline $\mathrm{H}_{2}^{2} \mathrm{SO}_{4} \quad 2$ & 41 cde A & 28 de $\mathrm{A}$ & 36 bc $\mathrm{B}$ & 59 a $A$ & $5 \mathrm{~b} \mathrm{~A}$ & $5 \mathrm{~b} \mathrm{~A}$ \\
\hline $\mathrm{H}_{2}^{2} \mathrm{SO}_{4}^{4} 6$ & 37 cdef A & 26 e $A$ & 54 ab A & 65 a $A$ & $3 \mathrm{~b} \mathrm{~A}$ & $4 \mathrm{~b} \mathrm{~A}$ \\
\hline $\mathrm{H}_{2}^{2} \mathrm{SO}_{4}{ }^{4} 10^{\prime}$ & 39 cdef A & 47 cde A & $38 \mathrm{~b} \mathrm{~A}$ & 39 ab A & $5 \mathrm{~b} \mathrm{~A}$ & $5 \mathrm{~b} \mathrm{~A}$ \\
\hline $\mathrm{H}_{2}^{2} \mathrm{SO}_{4}{ }^{4} 15^{\prime}$ & 51 bcd A & 53 bcd $A$ & 42 ab A & 25 bс B & $5 \mathrm{~b} \mathrm{~A}$ & $9 \mathrm{~b} \mathrm{~A}$ \\
\hline $\mathrm{H}_{2}^{2} \mathrm{SO}_{4}^{4} 20$ & 61 bc A & 73 ab A & 25 bc A & 10 cde $B$ & 5 b A & $6 \mathrm{~b} \mathrm{~A}$ \\
\hline $\mathrm{H}_{2} \mathrm{SO}_{4} 30^{\prime}$ & $68 \mathrm{ab} \mathrm{B}$ & 84 a $A$ & 1 e $A$ & 2 e $A$ & $4 \mathrm{~b} \mathrm{~A}$ & $5 \mathrm{~b} \mathrm{~A}$ \\
\hline $\mathrm{H}_{2}^{2} \mathrm{O} 70^{\circ} \mathrm{C}$ & 71 ab A & 66 abc $A$ & $11 \mathrm{~cd} \mathrm{~A}$ & 18 bcd A & $12 \mathrm{~b} \mathrm{~A}$ & $9 \mathrm{~b} \mathrm{~B}$ \\
\hline $\mathrm{H}_{2} \mathrm{O} 80^{\circ} \mathrm{C}$ & 87 a $A$ & 78 a $A$ & 6 de $A$ & 5 de $A$ & $1 \mathrm{~b} \mathrm{~B}$ & $9 \mathrm{~b} \mathrm{~A}$ \\
\hline $\mathrm{H}_{2} \mathrm{O}_{90}^{\circ} \mathrm{C}$ & $67 \mathrm{ab} A$ & 27 e $B$ & 7 de $A$ & 0 e $B$ & $11 \mathrm{~b} \mathrm{~A}$ & 42 a $A$ \\
\hline $\mathrm{KNO}_{3}(0,2 \%)$ & 24 ef $\mathrm{A}$ & 28 de $\mathrm{A}$ & 65 а $A$ & 63 а A & $9 \mathrm{~b} \mathrm{~A}$ & $4 \mathrm{~b} \mathrm{~A}$ \\
\hline $\mathrm{CV}(\%)$ & \multicolumn{2}{|c|}{16,43} & \multicolumn{2}{|c|}{0,98} & \multicolumn{2}{|c|}{48,21} \\
\hline
\end{tabular}

Revista Árvore, Viçosa-MG, v.36, n.1, p.01-06, 2012 
impedimento para o processo germinativo é o tegumento impermeável, assim como nas sementes de canafistula. A escarificação das sementes com lixa é um método que apresenta menor risco operacional aos funcionários dos viveiros e menor custo do que a escarificação ácida; no entanto, deve-se considerar a dificuldade de execução da escarificação com lixa em larga escala.

Sementes intactas, sem tratamentos para superação da dormência, permaneceram duras após o teste de germinação em taxa de $80 \%$, o que demonstra a necessidade de tratamento para a superação de dormência em sementes dessa espécie para a obtenção de germinação rápida e uniforme. O tratamento com água quente é uma importante forma de superar a dormência de sementes com impermeabilidade do tegumento à água, como sementes de sabiá e faveira; no entanto, a temperatura e o período de permanência na água são fatores determinantes no método (MARTINS et al., 1992; NASCIMENTO; OLIVEIRA 1999). A eficiência do ácido sulfúrico na superação da dormência e promoção da germinação em canafístula foi constada por vários autores. Porém, essa eficiência foi verificada ao se utilizarem diferentes períodos de imersão, como 4, 6 e 8min(BIANCHETTI; RAMOS, 1981)e 20 min(GUERRA et al., 1982). A diferença de resultados encontrados entre esses autores, para o tratamento que utiliza ácido sulfúrico ou água quente, pode ser devido às variações genéticas e ambientais entre os lotes utilizados. Espécies com ampla distribuição geográfica podem responder diferentemente aos tratamentos utilizados, em razão dos efeitos de adaptação e da origem (MARTINS; NAKAGAWA, 2008).

Em sementes com tegumento impermeável, tratamentos feitos com a utilização de ácido sulfúrico têm revelado bons resultados na superação da dormência; tal efeito foi registrado em sementes de sabiá, barbatimão e faveira (MARTINS et al., 1992; MARTINS; NAKAGAWA, 2008; NASCIMENTO et al., 2009).

As amostras que apresentam maiores pesos médios de matéria seca de plântulas normais são mais vigorosas. As sementes vigorosas proporcionam maior transferência de matéria seca de seus tecidos de reserva para o eixo embrionário na fase de germinação, originando plântulas com maior peso, em função do maior acúmulo de matéria (NAKAGAWA 1994). É importante observar que o uso de água quente $\left(70^{\circ} \mathrm{C}\right)$ pode ser um método promissor quando se trata de produção em pequena escala, o qual proporcionou valor de germinação médio de $62 \%$, plântulas vigorosas (Figura 3), sem o inconveniente de manipulação de produtos químicos, como o ácido sulfúrico, que pode causar intoxicação ao operador e danos ao meio ambiente.

Os patógenos encontrados em maiores porcentagens foram Pestalotia sp. (14\%) e Alternaria sp. (6\%); os demais fungos estavam presentes em menos de $1 \%$ das amostras. Segundo Oliveira et al. (2003), os principais fungos encontrados nas sementes de dois lotes de canafistula foram Trichoderma sp., Penicillium sp., Aspergillus niger e Fusarium sp., que de acordo com Mucci e Lasca (1986) podem causar danos às sementes de canafistula. Segundo Neergard (1997), os fungos pertencentes aos gêneros Fusarium, Phomopsis, Helmintosporium, Rhizoctonia, Colletotrichum e Cylindrocladium são patógenos responsáveis por mais de $90 \%$ da perda de sementes germinadas e no estádio de plântulas de plantas cultivadas. No entanto, há pouca informação sobre perdas econômicas significativas devido à presença de patógenos em sementes de espécies florestais. Fungos dos gêneros Fusarium e Colletotrichum são comprovadamente patógenos de sementes de muitas espécies de plantas (CARVALHO; MUCHOVEJ, 1991) e podem ser responsáveis pela grande variação na germinação das sementes (MACHADO, 1988). Curiosamente, após o armazenamento, detectou-se apenas o fungo Fusarium semitectum nas sementes armazenadas a $10^{\circ} \mathrm{C}$, em valor inferior a $1 \%$. As sementes armazenadas em ambiente não apresentaram qualquer manifestação de patógenos. De modo similar ao verificado em trabalho de Oliveira et al. (2003), a presença dos fungos nas sementes não impediu a germinação ou causou infecção visível das plântulas.

Nas sementes armazenadas em condições de laboratório (sem controle de temperatura) e em câmara a $10^{\circ} \mathrm{C}$, a maior porcentagem de sementes mortas ocorreu nos tratamentos com água quente a $90^{\circ} \mathrm{C}$ e escarificação com lixa, respectivamente. As baixas porcentagens de germinação nesses tratamentos e os tratamentos de imersão em água quente de 70 a $80^{\circ} \mathrm{C}$ promoveram a germinação, proporcionando baixo índice de sementes mortas (Tabela 1). O único patógeno detectado após 210 dias de armazenamento foi o fungo Fusarium semitectum, mas em valor inferior a $1 \%$.

Revista Árvore, Viçosa-MG, v.36, n.1, p.01-06, 2012 


\section{CONCLUSÕES}

Diante dos resultados, chegou-se às seguintes conclusões:

- Os melhores tratamentos para a superação da dormência, antes do armazenamento, das sementes de canafístula foram escarificação com lixa e imersão em ácido sulfúrico durante 15, 20 ou $30 \mathrm{~min}$.

- Após 210 dias de armazenamento, a imersão das sementes em água quente $\left(70\right.$ e $\left.80^{\circ} \mathrm{C}\right)$ foi mais eficiente para a promoção da germinação.

- Os fungos detectados nas sementes foram Pestalotia sp., Alternaria sp., Rhizopus sp., Nigrospora sp., Curvularia sp., Fusarium sp., Rhizoctonia sp., Aspergillus sp., Cladosporium sp. e Fusarium semitectum.

\section{REFERÊNCIAS}

BARNETT, H. L.; BARRY, B. H. Ilustrated genera of imperfect fungi. 2.ed. St Paul: Burgess Publishing Company, 1976.

BRASIL. Ministério da Agricultura, Pecuária e Abastecimento. Secretaria de Defesa Agropecuária. Regras para análise de sementes. Brasília: 2009. 399p.

BIANCHETTI, A.; RAMOS, A. Quebra de dormência em sementes de canafistula (Peltophorum dubium (Spreng) Taubert) Boletim de Pesquisa Florestal, n.3, p.77-83, 1981.

CARVALHO, W. L.; MUCHOVEJ, J. J. Fungos associados a sementes de essências florestais. Revista Árvore, v.15, n.2, p.173-178, 1991.

CARVALHO, P. E. R. Espécies florestais brasileiras: recomendações silviculturais, potencialidades e uso da madeira. Colombo: Embrapa, 1994. 640p.

DURIGAN, G. et al. Sementes e mudas de arvores tropicais. Campinas: Instituto Florestal, CIMP/SMA, 1997.
GUERRA, M. P. et al. Comportamento da canafístula (Peltophorum dubium (Sprengel) Taubert) em viveiro, submetida a diferentes métodos de quebra de dormência e semeadura. Boletim de Pesquisa Florestal, n.5, p.1-15, 1982.

MACHADO, J. C. Patologia de sementes: fundamentos e aplicações. Brasília: MEC/ESAL/ FAEP, 1988. 106p.

MARTINS, C. C.; NAKAGAWA, J. Germinação de sementes de Stryphnodendron adstringens

(Mart.) Coville de diferentes origens submetidas a tratamentos para superação de dormência.

Revista Árvore, v.32, n.6, p.1059-1067, 2008.

MARTINS, C. C.; CARVALHO, N. M.; OLIVEIRA, A. P. Quebra de dormência em sementes de sabiá (Mimosa caesalpinifolia Benth) Revista Brasileira de Sementes, v.14, n.1, p.5-8, 1992.

MUCCI, F. E. S.; LASCA, C. C. Flora fúngica de sementes de essências florestais nativas.

Fitopatologia Brasileira, v.11, n.2, p.352, 1986.

NAKAGAWA, J. Testes de vigor baseados na avaliação das plântulas. In: VIEIRA, R. D.; CARVALHO, N. M. (Eds.). Testes de vigor em sementes. Jaboticabal: FUNEP, 1994. p.49-86.

NASCIMENTO, M. P. S. B.; OLIVEIRA, M. E. A. Quebra de dormência de sementes de quatro espécies arbóreas. Acta Botânica Brasílica, v.13, p.129-137, 1999.

NASCIMENTO, I. L. et al. Superação da dormência em sementes de faveira (Parkia platycephala) Revista Árvore, v.33, n.1, p.35-45, 2009.

NEEGARD, P. Seed pathology. London: Mac Millan Press, 1997.v.2. 839p.

OLIVEIRA, L. M.; DAVIDE, A. C.; CARVALHO, M. L. M. Avaliação de métodos para quebra da dormência e para desinfestação de sementes de canafístula (Peltophorum dubium (Sprengel) Taubert. Revista Árvore, v.27, n.5, p.597-603, 2003. 